\title{
Influence of age, menopause, pelvic muscle exercises, urethral hypermobility and concomitant surgery on the outcomes after the transobturator tape procedure (factors effecting TOT outcomes)
}

\author{
Wpływ wieku, menopauzy, ćwiczeń mięśni miednicy, zwiększonej ruchomości cewki moczowej, zabiegów \\ chirurgicznych na wyniki operacii z zastosowaniem taśmy przeprowadzonej przez ołwory zasłonowe \\ (czynniki wpływajqce na wyniki operacii z zastosowaniem metody TOT)
}

Ali Yavuzcan¹, 2, Gazi Yıldız, Yusuf Üstün², Raşit Altıntaş³, Mete Çağlar², Pınar Yıldız ${ }^{1}$ Hüseyin Sert ${ }^{1}$ Serdar Dilbaz², Selahattin Kumru²

${ }^{1}$ Department of Obstetrics \& Gynecology, Bucak State Hospital;

Head of Department: Gazi Yıldız

${ }^{2}$ Department of Obstetrics \& Gynecology, Duzce University Faculty of Medicine;

Head of Department: Selahattin Kumru

${ }^{3}$ Department of Urology, Bucak State Hospital;

Head of Department: Raşit Altıntaş

Przegląd Menopauzalny 2013; 2: 105-110

\section{Summary}

Objectives: We evaluated age, menopause, Q-tip and urinary stress tests performed on an outpatient basis before the transobturator tape (TOT) procedure, preoperative Kegel exercises, and vaginal surgeries performed concomitantly with the TOT procedure for their impact on symptomatic relief and complications in patients undergoing the TOT procedure.

Aim of the study: Data including age, parity, menopausal status, concomitant vaginal surgery, complications, whether or not preoperative Kegel exercises were administered and urinary (cough) stress test and Q-tip test were performed, were retrieved from the patient charts and hospital records.

Material and methods: The medical records of women, who underwent the TOT procedure for SUI in the Department of Obstetrics and Gynecology in Bucak State Hospital between January 2009 and November 2012 were reviewed.

Results: No significant difference was observed between patients below and at or above 50 years of age in terms of success rate and complication rate ( $p=1.00$ and $p=0.351$, respectively). There was a tendency for menopausal women to have a higher success rate ( $93.3 \%$ vs. $75 \%)$, this did not reach a statistical significance $(p=0.09)$. Urethral hypermobility did not significantly influence the success rate and complication rate $(p=0.694)$. Kegel exercises did not significantly influence the success rate and complication rate $(p=0.694)$. Vaginal surgeries performed concomitantly with the TOT procedure did not significantly influence complication rate $(p=0.454)$.

Conclusions: The TOT procedure brings about the high success and low complication rates. Prospective, randomized, controlled studies on a larger number of patients are needed to clearly identify factors that would raise the success rate and reduce the complication rate.

Key words: age, concomitant surgery, menopause, Kegel exercises, transobturator tape, urethral hypermobility.

Address for correspondence:

Ali Yavuzcan, M.D., Department of Obstetrics and Gynecology, Düzce University Faculty of Medicine, 81000, Konuralp/Duzce-Turkey, tel. +90 (380) 542 13 90, GSM +90 (532) 63454 31, e-mail: draliyavuzcan@yahoo.com 


\section{Introduction}

Objectively reproducible involuntary urinary leakage is termed urinary incontinence (UI) which represents a hygienic and social problem [1]. The incidence of stress urinary incontinence (SUI) increases with age, affecting about $45 \%$ of women around the age of 60 years in Europe [2]. The pelvic floor dysfunction and neurological deficits become more prevalent in women with increasing average lifespan. Advanced age and menopause are known to be associated with an increased prevalence of cystocele, rectocele, cysto-rectocele or descensus uteri in association with pelvic floor weakness. Vaginal surgery due to pelvic organ prolapse is more common in the elderly. Vascular disorders of the central nervous system become more prevalent with the increasing age, leading to a neurological impairment. Urinary incontinence caused by neurological factors impairs the functional status of the patients. Therefore, SUI and mixed urinary incontinence (MUI) represent a significant health concern with a profound effect on the patients' quality of life $[3,4]$. On the other hand, $\mathrm{UI}$ is not considered as a part in the natural course of senescence or menopause [5].

True SUI is an involuntary urine leakage as a result of increased intravesical pressure exceeding urethral pressure in the absence of detrusor contraction as measured by urodynamic studies. It is a result of hypermobility of the vesicourethral segment caused by pelvic floor weakness [6]. Other risk factors for SUI include sex, parity, race, menopause, smoking, constipation, obesity and previous history of gynecological surgery [7]. Pregnan$c y$, childbirth, obesity and collagen abnormalities are known to predispose to SUI [8]. The diagnosis of SUI is based on the patient's history, complaints and urinary stress tests. A urinary stress test and Q-tip test demonstrating urethral hypermobility are adjunctive tests used to diagnose SUI. Utility of urodynamic assessments has become debatable for this aim [9]. The patients can be given pelvic muscle exercises (Kegel exercises) as the first-line treatment for SUl. Conservative therapies such as pelvic floor electrical stimulation, biofeedback and mechanical devices (pessary) are also employed [10]. However, most patients either fail to use or do not benefit from conservative therapies, in which case various surgical treatment options might be attempted. Introduction of a minimally invasive midurethral sling procedure has changed the selection criteria for surgery and this made anti-incontinence surgery a more frequently performed procedure [11]. The American Association of Urology reviewed long-term outcomes and reported retropubic suspension and midurethral sling procedure to be effective interventions in the surgical management of SUI [12]. However, traditional colposuspension surgery and vaginal sling procedure have increasingly lost their reputation due to high morbidity and a low overall success rate associated with these procedures. In the last decade, midurethral synthetic sling procedures such as the transobturator tape (TOT) procedure have become the most commonly performed surgical method [13].

\section{Aim of the study}

In this study, we evaluated age, menopause, Q-tip and urinary stress tests performed on an outpatient basis before the TOT procedure, preoperative Kegel exercises, and vaginal surgeries performed concomitantly with the TOT procedure for their impact on symptomatic relief and complications in patients undergoing the TOT procedure for SUI.

\section{Material and methods}

In this study, we retrospectively reviewed the medical records of 53 women, who underwent the TOT procedure for SUI in the Department of Obstetrics and Gynecology in Bucak State Hospital, Burdur, between January 2009 and November 2012. Medical data including age, parity, menopausal status, concomitant vaginal surgery, complications, whether or not preoperative Kegel exercises were administered and urinary (cough) stress test and Q-tip test were performed, were retrieved from the patient charts and hospital records.

Patients, who were suffering from urine leakage for the last 3 months with activities that increase intra-abdominal pressure (i.e. coughing, sneezing, and weight lifting), and who seek treatment for these complaints, were included in this study. Patients with a neurological disorder that would affect the bladder function, patients with mixed or urge incontinence or those with hyperactive bladder symptoms, patients with a history of previous surgery for SUI, patients who suffer from urine leakage in the absence of an increase in intra-abdominal pressure or while standing, patients with nocturia ( $\geq 2$ times per night) and those with limited mobilization and those undergoing pelvic radiotherapy, patients receiving those medications (i.e. calcium channel blockers, benzodiazepines, diuretics) that could cause urinary incontinence as mentioned in the package insert, patients with alcohol/ substance dependence, patients with urinary tract infections or those with obstructive or functional disorder of the urinary tract were excluded from the study. For statistical purposes, patients were divided into two groups as those below 50 years $(<50)$ and those at or above 50 years $(\geq 50)$ of age. Patients were considered menopausal in the absence of menstrual flow for 6 months.

The patients were asked the following questions to establish the diagnosis of SUI as recommended by the Association of Women's Health, Obstetric and Neonatal Nurses (AWHONN): i) Do you ever leak urine/water when you don't want to?; ii) Do you ever leak urine/water when you cough, laugh, or exercise?; iii) Do you ever use pads, 
tissue, or cloth in your underwear to catch urine? [14]. Patients who positively responded to these questions subsequently underwent gynecological examination. Twentyseven patients were subjected to a urinary stress (cough) test during which they were asked to cough after filling the bladder with 200-300cc fluid. The test was considered positive upon observing fluid release. The patients then underwent a Q-tip test to detect urethral hypermobility. Urethral hypermobility was considered to be present when the straining angle exceeded $30^{\circ}$. The diagnosis of SUI was established when both tests were found to be positive and patients with positive test results were grouped as patients with positive preoperative tests.

Twenty-seven out of 53 patients were given Kegel exercises for 12 to 18 months before the operation. Twenty-seven patients were given pelvic floor muscle training and encouraged to perform 8 to 12 sets of contractions per day for three or four times a week, maintaining each contraction for 6-8 seconds as recommended by HaySmith et al. [15].

Twenty-six patients were not given Kegel exercises or any other means of conservative therapy. These 26 patients also did not undergo a preoperative urinary stress (cough) test or Q-tip test.

All patients provided written informed consent prior to the operation. Patients were administered preoperative antibiotic prophylaxis with $1 \mathrm{~g}$ Cefazolin. Foley urinary catheters were removed at 24 hours postoperatively.

Delorme's inside-out surgical technique was employed [16]. Macroporous monofilament polypropylene mesh was used in transobturator sling procedures.

Tab. I. Demographic characteristics of the patients

\begin{tabular}{|c|c|c|}
\hline \multirow[t]{2}{*}{ Age (mean \pm standard deviation) } & \multicolumn{2}{|c|}{$48.38 \pm 10.990$} \\
\hline & $n$ & $\%$ \\
\hline 50 years and above & 27 & 50.9 \\
\hline Below 50 years & 26 & 49.1 \\
\hline \multicolumn{3}{|l|}{ Parity } \\
\hline 1 & 4 & 7.5 \\
\hline 2 & 14 & 26.4 \\
\hline 3 & 24 & 45.3 \\
\hline 4 & 7 & 13.2 \\
\hline 5 & 4 & 7.5 \\
\hline Menopause & 20 & 37.7 \\
\hline Success rate of the TOT procedure & 46 & 86.8 \\
\hline \multicolumn{3}{|l|}{ Complications } \\
\hline leg pain & 2 & 3.8 \\
\hline bladder/urethra trauma & 2 & 3.8 \\
\hline none & 49 & 92.5 \\
\hline \multicolumn{3}{|l|}{ Concomitant vaginal surgery } \\
\hline perineoplasty & 9 & 17.0 \\
\hline cysto-rectocele & 7 & 13.2 \\
\hline cystocele & 4 & 7.5 \\
\hline none & 33 & 62.3 \\
\hline Preoperative test (Stress test + Q-Tip test) & 28 & 52.8 \\
\hline Preoperative Kegel exercises & 28 & 52.8 \\
\hline
\end{tabular}

After removal of the urinary catheters, the patients were followed in the regular ward until the patient had spontaneous urination. The patients were asked the same questions as in the preoperative assessment and were subjectively evaluated if the operation relieved their complaints. Same questions as recommended by AWHONN [14] were re-administered on Day 7 and Day 30 in order to evaluate the persistence of SUI. The operation was considered successful if the patient remained "dry" and responded negatively to the questions before the discharge, on Days 7 and 30 as compared to positive responses before the procedure. Operation failure was considered if the patient did not report total dryness and responded "yes" to any of the above-mentioned questions.

\section{Statistical analysis}

The data were analyzed using SPSS 19.0 statistical software package. Descriptive statistics included mean, standard deviation, and percentage to indicate the distribution of data. All variables that are considered to have affected success and complications were analyzed by Pearson's $\chi^{2}$ test and Fisher's exact test. $P<0.05$ was considered statistically significant.

\section{Results}

Analysis of the demographic data revealed a mean age of $43.3 \pm 10.9$ years and $50 \%(n=27)$ of the patients were above 50 years of age. Of the patients, $37.7 \%(n=20)$ were menopausal. For the whole group of patients, the success rate of the TOT procedure was $86.8 \%$ and the complication rate was $7.5 \%$. Twenty patients (37.7\%) underwent perineoplasty or other surgeries for cystocele or cysto-rectocele concomitantly with the TOT procedure. Of the patients, $52.8 \%(n=28)$ underwent a preoperative stress test and Q-tip test, and 52.8\% $(n=28)$ were given Kegel exercises before the operation (Tab. I).

We evaluated the success rate and complication rate of the TOT procedure in relation with the patient age and no significant difference was observed between patients below and at or above 50 years of age $(p=1.00$ and $p=0.351$, respectively) (Tab. II). Although

Tab. II. The association of the patient age and menopause status with the success rate and complication rate of the TOT procedure

\begin{tabular}{|c|c|c|c|c|}
\hline & $\begin{array}{c}\text { Complication } \\
n(\%)\end{array}$ & $\begin{array}{c}p \\
\text { value* }\end{array}$ & $\begin{array}{c}\text { Success rate } \\
n(\%)\end{array}$ & $\begin{array}{c}p \\
\text { value* }\end{array}$ \\
\hline age $<50$ & $3(1.1)$ & \multirow{2}{*}{0.351} & $23(85.1)$ & \multirow{2}{*}{1} \\
\hline age $\geq 50$ & $1(3.8)$ & & $23(88.4)$ & \\
\hline menopause & $2(10.0)$ & \multirow[b]{2}{*}{0.627} & $15(75.0)$ & \multirow[b]{2}{*}{0.900} \\
\hline $\begin{array}{l}\text { premeno- } \\
\text { pause }\end{array}$ & (6.0) & & 31 (93.3) & \\
\hline
\end{tabular}

*Using Fisher's exact test; $p<0.05$ was considered statistically significant 
there was a tendency for menopausal women to have a higher success rate ( $93.3 \%$ vs. $75 \%)$, this did not reach statistical significance $(p=0.09)$ (Tab. III). Performing preoperative clinical tests did not significantly influence the success rate as well as the complication rate $(p=0.694)$ (Tab. IV). Likewise, Kegel exercises did not significantly influence the success rate and complication rate $(p=0.694)$ (Tab. III).

Vaginal surgeries performed concomitantly with the TOT procedure did not significantly influence the complication rate $(p=0.454)$ (Tab. IV). Addition of perineoplasty or other procedures for rectocele and cysto-rectocele did not significantly influence the success rate $(p=0.443, p=0.227$, $p=0.588$, respectively) (Tab. IV).

\section{Discussion}

Midurethral slings have become increasingly popular compared to other surgical methods in the treatment of SUI. There are many different procedures for retropubic sling placement [17]. During this procedure, passage of the trocar through the retropubic space may lead to complications such as bladder perforation, vessel injury and bowel injury. The TOT procedure, which is based on mesh placement through the transobturator canal and which is thought to offer an easy-to-perform procedure with a lower complication rate, was first introduced in 2001 . In DeLorme's method, trocar is inserted through a $1-2 \mathrm{~cm}$ wide skin incision during mesh placement using an outside-in approach. Vaginal mucosa is then dissected off the urethra and bladder neck from both sides and the mesh is placed tension-free in transverse position [16]. de Leval later described the inside-out approach which involves trocar insertion out through the incision [18].

The aim of the TOT procedure is to alleviate all symptoms of SUI and to improve the patient's quality of life. Thus, factors affecting the success rate and the complication rate have been extensively evaluated in numerous studies $[13,19]$. Various parameters are available to evaluate the outcomes of the treatment. An objective cure of SUI is defined as the absence of incontinence in

Tab. III. The association of preoperative clinical tests (urinary stress test and Q-tip test) and Kegel exercises with the success rate of the TOT procedure

\begin{tabular}{lcc}
\hline & $\begin{array}{c}\text { Success rate } \\
n(\%)\end{array}$ & $\begin{array}{c}p \\
\text { value* }\end{array}$ \\
\cline { 1 - 2 } $\begin{array}{lcc}\text { Preoperative clinical tests } \\
\text { (Stress test + Q-tip) performed }\end{array}$ & $25(89.3)$ & \\
\cline { 1 - 2 } $\begin{array}{lll}\text { Preoperative clinical tests } \\
\text { not performed }\end{array}$ & $21(84.0)$ & \\
\cline { 1 - 2 } Kegel exercises performed & $25(89.3)$ & \multirow{2}{*}{0.694} \\
\cline { 1 - 2 } Kegel exercises not performed & $21(84.0)$ & \\
\hline
\end{tabular}

*Using Fisher's exact test; ${ }^{*} p<0.05$ was considered statistically significant the cough stress test [19]. Incontinence screening questions of the AWHONN assess the patient for the presence of SUI in her daily life [14]. This assessment tool also allows the surgeon to evaluate the treatment success by the administration of this questionnaire before and after the surgery. Delorme reported 98\% cure rate with the TOT procedure [16]. Costa et al. reported a cure rate of $80.5 \%$ in a series of 183 patients [20]. The success with the TOT procedure ranges between $51 \%$ and 95\% [21]. In our study, treatment success was achieved in 46 out of 53 patients (86.8\%) on assessments performed before the discharge and at days 7 and 30, postoperatively, and the patients reported total relief of symptoms of SUI. This success rate is in conformity with those reported in the literature [13, 20, 21].

Previous studies have shown that the TOT procedure might be associated with some complications such as prolonged bleeding, surgical site infection, re-operation due to mesh erosion and leg/groin pain $[8,13]$. In our study, complications occurred in 4 patients, 2 (3.8\%) of which sustained bladder trauma and the other 2 (3.8\%) had leg pain. Similar to our study, Taweel et al. employed Delorme's procedure and evaluated 52 patients. None of the patients have sustained bladder trauma or had leg pain [22]. Dursun et al. employed the same methods and did not observe bladder trauma or leg pain [13]. We think that high rates of bladder trauma and leg pain observed in our study could be explained by the limited surgical practice.

In our study, treatment success and complication rate were not affected by menopause $(p=0.627$ and $p=0.090$, respectively). Dursun et al. found the TOT procedure to be more effective in premenopausal women [13]. There are considerably limited studies in the literature addressing the influence of menopause on the outcomes of the TOT procedure. Rechberger et al. reported that the menopausal status unfavorably affects the outcomes of the TOT procedure [23]. A small number of patients in our study is thought to have prevented the net effect of menopausal status on the outcomes after the TOT procedure to become apparent.

Tab. IV. The association of concomitant vaginal surgeries with the complication rate and success rate of the TOT procedure

\begin{tabular}{|c|c|c|c|c|}
\hline & $\begin{array}{c}\text { Complication } \\
n(\%)\end{array}$ & $\underset{\text { value }^{*}}{p}$ & $\begin{array}{c}\text { Success } \\
\text { rate } \\
\text { n (\%) }\end{array}$ & $\stackrel{p}{\text { value }^{\star}}$ \\
\hline $\begin{array}{l}\text { Concomitant } \\
\text { surgery }\end{array}$ & $0(0.0)$ & 0.454 & $15(75.0)$ & 0.900 \\
\hline cystocele & & & $3(75.0)$ & 0.443 \\
\hline rectocele & & & $5(71.4)$ & 0.227 \\
\hline $\begin{array}{l}\text { perine- } \\
\text { oplasty }\end{array}$ & & & 7 (77.7) & 0.588 \\
\hline $\begin{array}{l}\text { No concomi- } \\
\text { tant surgery }\end{array}$ & $4(12)$ & & 31 (93.3) & \\
\hline
\end{tabular}


There are reports indicating that advanced age could negatively affect the success rate of the TOT procedure $[23,24]$. In contrast, de Toledo et al. reported that patient age did not affect the outcomes of the TOT procedure [24]. In our study, we did not find any difference between patients below and at or above 50 years of age in terms of treatment success and complication rates, a finding which is in conformity with that in the study by de Toledo et al. ( $p=0.351$ and $p=1.000$, respectively).

Patient's history and voiding history are sufficient to establish the diagnosis of SUI. This also excludes nonstress reasons of urinary incontinence. Urodynamic testing is recommended in patients with urine leakage in the absence of increase in intra-abdominal pressure or at standing position, in patients with a history of nocturia ( $\geq 2$ times per night) or to evaluate patients for urge incontinence, overflow incontinence, intrinsic sphincter insufficiency or increased urine production [9]. There is no evidence indicating that preoperative urodynamic testing is associated with better treatment outcomes in patients with uncomplicated SUI [9]. Valsalva leak point pressure used in urodynamic studies was shown not to be associated with the operation success [25]. In the United States, urodynamic testing is not recommended in addition to the urinary stress test and Q-tip test which are performed on an outpatient basis in patients with uncomplicated SUI. Urodynamic testing has been shown to increase the treatment costs in return for no significant improvement in the treatment outcomes [26]. Recently, in 2013, Lemack et al. indicated that urodynamic testing has failed to demonstrate incontinence in 1 of 8 patients who were scheduled for surgery with the diagnosis of SUI [27]. We did not perform urodynamic testing in our study. However, 28 patients on an outpatient basis underwent a preoperative urinary (cough) stress test and Q-tip test to evaluate urethral hypermobility. In our study, none of these tests performed preoperatively in an outpatient setting were significantly associated with treatment success ( $p=0.694)$.

There are various considerations on the influence of urethral hypermobility on the treatment outcomes after the TOT procedure. In previous studies, outcomes after the TOT procedure are influenced by the increased mobility of the proximal urethra [25-27]. Paick et al. evaluated 159 patients and similar to our study, urethral hypermobility was not found to be a significant factor affecting the treatment outcomes of the TOT procedure [28]. This suggests that the TOT procedure is effective not only in patients with urethral hypermobility but also in those with intrinsic sphincter insufficiency. None of our patients had intrinsic sphincter insufficiency; however, although we did not perform urodynamic testing, some patients might have intrinsic sphincter insufficiency and might benefit from the operation.

Systematic reviews in the literature indicated that pelvic muscle exercises such as Kegel exercises have de- creased the number of urination compared to controls and also improved the symptoms of SUI [29]. However, SUI is unlikely to be cured by Kegel exercises. Nevertheless, pelvic muscle exercises performed for at least 3 months may be beneficial in patients with SUI between 40-60 years of age although this benefit may vary depending on the population and the methods used [9]. Despite the assumption that strengthening pelvic floor muscles lying across the bottom of the pelvis as a hammock might positively influence the treatment outcomes after the TOT procedure, the success rate in patients performing preoperative Kegel exercises was not found to be significantly higher in our study $(p=0.694)$. The number of studies evaluating the influence of preoperative Kegel exercises on the success rate of the TOT procedure is limited. Studies on a large series of patients are needed to suggest Kegel exercises as a substitute for the operation in elderly patients with a high surgical risk and advanced age or to confirm the effectiveness of Kegel exercises until the time of surgery [29].

Richter et al. reported that other surgeries performed concomitantly with the TOT procedure decreased subjective success after the operation [26]. In contrast, Chai et al. reported in a study in 2012 that concomitant surgery did not increase the complication rate. Furthermore, they reported that cystocele or rectocele repair, or perineoplasty performed concomitantly with transobturator or midurethral sling procedures did not reduce the success rate of anti-incontinence surgery and that the surgeons should be encouraged to perform concomitant vaginal surgeries [30]. In our study, 4 patients underwent cystocele repair, 7 - rectocele repair and 9 - perineoplasty concomitantly with the TOT procedure. None of these patients developed complications. We also evaluated the individual influence of each type of concomitant surgery on the treatment success of the TOT procedure and none of these surgeries appeared to have a significant effect on the treatment outcome ( $p=0.443, p=0.227, p=0.588$, respectively).

\section{Conclusions}

The TOT procedure brings about high success and low complication rates. Age, menopausal status, preoperative Kegel exercises, preoperative clinical tests (Q-tip test and urinary stress test) and concomitant surgery did not alter the complication and success rates. Prospective, randomized, controlled studies on a larger number of patients are needed to clearly identify the factors that would raise the success rate and reduce the complication rate.

\section{References}

1. Abrams P, Cardozo L, Fail M, et al.; Standardisation Sub-committee of the International Continence Society. The standardisation of terminology of lower urinary tract function: report from the Standardisation Subcommittee of the International Continence Society. Neurourol Urodyn 2002; 21: 167-78. 
2. Hunskaar S, Lose G, Sykes D, Voss S. The prevalence of urinary incontinence in women in four European countries. BJU Int 2004; 93: 324-30.

3. Dutkiewicz S, Kapusta K. Risk factors and quality of life in urinary incontinence females in the Care and Medical Centre in Kielce. Prz Menopauz 2011; 15: 493-9.

4. Klutke C, Siegel S, Carlin B, et al. Urinary retention after tension-free vaginal tape procedure: incidence and treatment. Urology 2001; 58 : 697-701.

5. Herzog AR, Fultz NH. Prevalence and incidence of urinary incontinence in community dwelling populations. J Am Geriatr Soc 1990; 38: 273-81.

6. Gill BC, Moore C, Damaser MS. Postpartum stress urinary incontinence: lessons from animal models. Expert Rev Obstet Gynecol 2010; 5: 567-80.

7. Delancey JO. Why do women have stress urinary incontinence? Neurourol Urodyn 2010; 29 Suppl 1: S13-7.

8. Latthe PM, Patodi M, Constantine G. Transobturator tape procedure in stress urinary incontinence: UK experience of a district general hospital. Obstet Gynaecol 2007; 27: 177-80.

9. Jelovsek JE, Reddy J. Stress urinary incontinence in women: Preoperative evaluation for a primary procedure. Up To Date. Literature review current through: Jan 2013.

10. Chmielewska D, Kwaśna K, Piecha M, et al. Selected methods of conservative treatment of stress urinary incontinence: current views. Part 1. Prz Menopauz 2012; 16: 264-8.

11. Joo YM, Choe JH, Seo JT. One-Year Surgical Outcomes and Quality of Life after Minimally Invasive Sling Procedures for the Treatment of Female Stress Urinary Incontinence: TVT SECUR(R) vs. CureMesh(R). Korean J Urol 2010; 51: 337-43.

12. Dmochowski RR, Blaivas JM, Gormley EA, et al.; Female Stress Urinary Incontinence Update Panel of the American Urological Association Education and Research, Inc, Whetter LE. Update of AUA guideline on the surgical management of female stress urinary incontinence. J Urol 2010; 183: 1906-14.

13. Dursun P, Bildaci TB, Zeyneloglu HB, et al. Transobturator tape operation is more effective in premenopausal women than in postmenopausal women with stress incontinence. Korean J Urol 2011; 52: 612-5.

14. Association of Women's Health, Obstetric and Neonatal Nurses (AWHONN). Continence for Women - Evidence-based practice guideline. Washington (DC). AWHONN; 2000

15. Hay-Smith J, Berghmans BK. Adult conservative management. In: Incontinence, 4th ed. Abrams P, Cardozo L, Khoury S, Wein A (eds.). Health Publications Ltd, Paris 2009.

16. Delorme E. Transobturator urethral suspension: mini-invasive procedure in the treatment of stress urinary incontinence in women. Prog Urol 2001; 11: 1306-13.

17. Ulmsten $U$, Henriksson L, Johnson P, Varhos G. An ambulatory surgical procedure under local anesthesia for treatment of female urinary incontinence. Int Urogynecol J Pelvic Floor Dysfunct 1996; 7: 81-5.
18. de Leval J. Novel surgical technique for the treatment of female stress urinary incontinence: transobturator vaginal tape inside-out. Eur Urol 2003; 44: 724-30.

19. Zimmern PE. How do you define success in stress urinary incontinence treatment? Can Urol Assoc J 2012; 6: 127-8.

20. Costa P, Grise P, Droupy S, et al. Surgical treatment of female stress urinary incontinence with a trans-obturator-tape (T.O.T.) Uratape: short term results of a prospective multicentric study. Eur Urol 2004; 46: 102-6.

21. Maroto RJ, Gorraiz MO, Bueno JJ M, et al. Transobturator adjustable tape (TOA) permits to correct postoperatively the tension applied in stress incontinence surgery. Int Urogynecol J Pelvic Floor Dysfunct 2009; 20: 797-805.

22. Taweel WA, Rabah DM. Transobturator tape for female stress incontinence: follow-up after 24 months. Can Urol Assoc J 2010; 4: 33-6.

23. Rechberger T, Futyma K, Jankiewicz K, et al. Body mass index does not influence the outcome of anti-incontinence surgery among women whereas menopausal status and ageing do: a randomised trial. Int Urogynecol J 2010; 21: 801-6.

24. de Toledo LG, Cabral PH, Casella ML, et al. Prognostic value of urethra mobility and valsalva leak point pressure for female transobturator sling procedure. Int Braz J Urol 2012; 38: 667-73.

25. Weber AM, Taylor RJ, Wei JT, et al. The cost-effectiveness of preoperative testing (basic office assessment vs. urodynamics) for stress urinary incontinence in women. BJU Int 2002; 89: 356-63.

26. Richter HE, Litman HJ, Lukacz ES, et al.; Urinary Incontinence Treatment Network. Demographic and clinical predictors of treatment failure one year after midurethral sling surgery. Obstet Gynecol 2011; 117: 913-21.

27. Lemack GE, Litman HJ, Nager C, et al.; Urinary Incontinence Treatment Network. Preoperative clinical, demographic, and urodynamic measures associated with failure to demonstrate urodynamic stress incontinence in women enrolled in two randomized clinical trials of surgery for stress urinary incontinence. Int Urogynecol J 2013; 24: 269-74.

28. Paick JS, Cho MC, Oh SJ, et al. Is proximal urethral mobility important for transobturator tape procedure in management of female patients with stress urinary incontinence? Urology 2007; 70: 246-50.

29. Dumoulin C, Hay-Smith J. Pelvic floor muscle training versus no treatment for urinary incontinence in women. A Cochrane systematic review. Eur J Phys Rehabil Med 2008; 44: 47-63.

30. Chai TC, Kenton K, Xu Y, et al. Effects of concomitant surgeries during midurethral slings (MUS) on postoperative complications, voiding dysfunction, continence outcomes, and urodynamic variables. Urology 2012; 79: 1256-61. 